\title{
Associations between Inter-Limb Asymmetries in Jump and Change of Direction Speed Tests and Physical Performance in Adolescent Female Soccer Players
}

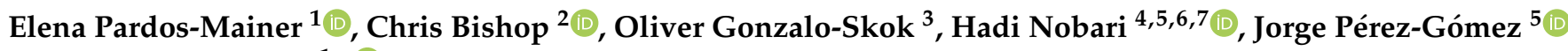 \\ and Demetrio Lozano ${ }^{1, * \mathbb{D}}$ \\ 1 Health Sciences Faculty, Universidad San Jorge, Autov A23 km 299, 50830 Villanueva de Gállego, \\ 50830 Zaragoza, Spain; epardos@usj.es \\ 2 Faculty of Science and Technology, London Sports Institute, London NW4 4BT, UK; C.Bishop@mdx.ac.uk \\ Head of Return to Play, Sevilla Futbol Club, 41005 Sevilla, Spain; oligons@hotmail.com \\ 4 Department of Physical Education and Sports, University of Granada, 18010 Granada, Spain; \\ hadi.nobari1@gmail.com \\ 5 HEME Research Group, Faculty of Sport Sciences, University of Extremadura, 10003 Cáceres, Spain; \\ jorgepg100@gmail.com \\ 6 Department of Exercise Physiology, Faculty of Sport Sciences, University of Isfahan, Isfahan 81746-7344, Iran \\ 7 Sports Scientist, Sepahan Football Club, Isfahan 81887-78473, Iran \\ * Correspondence: dlozano@usj.es; Tel.: +34-607-417-795
}

Citation: Pardos-Mainer, E.; Bishop, C.; Gonzalo-Skok, O.; Nobari, H.;

Pérez-Gómez, J.; Lozano, D.

Associations between Inter-Limb Asymmetries in Jump and Change of Direction Speed Tests and Physical Performance in Adolescent Female Soccer Players. Int. J. Environ. Res. Public Health 2021, 18, 3474. https:// doi.org/10.3390/ijerph18073474

Received: 23 February 2021

Accepted: 25 March 2021

Published: 27 March 2021

Publisher's Note: MDPI stays neutral with regard to jurisdictional claims in published maps and institutional affiliations.

Copyright: (c) 2021 by the authors. Licensee MDPI, Basel, Switzerland. This article is an open access article distributed under the terms and conditions of the Creative Commons Attribution (CC BY) license (https:// creativecommons.org/licenses/by/ $4.0 /)$.

\begin{abstract}
The association between asymmetries in jump and change of direction (COD) with physical performance in several sports show inconclusive results. The purposes of this study were to: (1) measure inter-limb asymmetries in three distinct groups in adolescent female soccer players and, (2) to determine the association between inter-limb asymmetries and physical performance in different age groups. Fifty-four players were distributed in three age groups: U-18, U-16 and U-14. All of them performed a series of jumps, sprints and change of direction speed tests. Asymmetries were assessed as the percentage difference between limbs, with the equation: 100/Max value (right and left) * in value (right and left) ${ }^{*}-1+100$. Mean inter-limb asymmetries were $2.91 \%, 4.82 \%$ and $11.6 \%$ for $180^{\circ} \mathrm{COD}$, single leg hop and single leg countermovement jump tests respectively, but higher percentages of asymmetries were observed in many players individually. U-18 and U-16 showed significant differences on $180^{\circ}$ left COD compared to U-14. Effect size (ES): 0.80 and 0.74, respectively; U-18 presented differences on single left leg hop test compared to U-14, ES: -0.72 ; U-16 also showed differences on $40 \mathrm{~m}$ speed compared to U-14, ES 0.87 (All $p<0.05$ ). Jumping and COD physical tests show asymmetries in adolescent female soccer players, but these asymmetries do not interfere with physical performance. The largest asymmetry was observed in the single leg countermovement jump, and no asymmetries between groups were found. Due to the high variability in the direction of asymmetries, it is recommended to consider players' individual asymmetries for designing specific training programs.
\end{abstract}

Keywords: athletic performance; youth sports; females; football

\section{Introduction}

Women's football has witnessed a notable increase in popularity during the last decade [1], particularly at the youth level, where a $\sim 4 \%$ increase in participation has been observed in the last 5 years [1]. Such impact has resulted in both increased demands during competition and training, as well as greater skill levels during matches [2]. Given these changes to the youth female game, a better understanding of the physical demands players face face across different age categories seems warranted.

In soccer, many high-intensity actions are performed unilaterally such as: jumping, sprinting, changing direction and kicking [3,4]. Given the prevalence of these actions occur- 
ring on one side, and the associated positional differences in soccer, inter-limb asymmetries should be expected in athletes who compete in this sport. Inter-limb asymmetries have been a reference on researches in latest years, it means to the concept of comparing the performance or function between limbs [5]. Literature has showed the requirement to investigate the connection between asymmetry and measures of physical performance [6-8], as the prevalence of asymmetry alone provides us with limited information as to the impact on athletic performance. Previous research in team sport athletes has shown that asymmetry may simply be a by-product of competing in a single sport over time [9]. Furthermore, the existing evidence base is still unclear as to whether asymmetry is consistently a problem for team sport athletes.

Only three studies have investigated the relationship between inter-limb asymmetries and measures of physical performance in female soccer players $[6,10,11]$. Bishop et al. [10] showed jump height asymmetry of $9.2 \%$ in the unilateral drop jump, which showed significant associations with linear sprint $(\mathrm{r}=0.52-0.58)$ and change of direction (COD) speed $(r=0.52-0.66)$ tests in adult female soccer players. Otherwise, no relationships were found between countermovement jump (CMJ) asymmetry and linear or COD speed. Similarly, Bishop et al. [6], found jump height asymmetry of $12.5 \%$ from the unilateral CMJ was associated with reduced speed performance $(r=0.49-0.59)$ in academy youth female soccer players. In contrast, Loturco et al. [11] showed jump height asymmetry of $9.8 \%$ and $10.6 \%$ from the unilateral squat jump and CMJ respectively, with no association with speed and power performance in professional female soccer players. Thus, with this conflicting evidence and lack of studies in female soccer players, it is not obvious if the differences in results are linked to the level (i.e., youth vs. professional), or motor activities performed (i.e., unilateral vs. bilateral horizontal or vertical jumps, straight running vs. COD). Thus, more researches are necessary to establish a correlation between inter-limb asymmetry and physical performance, specifically in adolescent female soccer players.

Inter-limb asymmetries has also been associated with injury risk [12,13], highlighting the important to analyse the effect of exercise-induced fatigue during training or sport practice due to inter-limb asymmetries on the risk of injuries [12,14]. Some studies have observed that greater inter-limb asymmetries and lower physical fitness showed a higher predisposition to injury [15]. It is known that athletic performance is influenced by players fatigue and it could be accentuated by asymmetries [7-16]. A reduced athletic performance was found with only $5 \%$ differences inter-lib asymmetries [7], however, other studies did not find a relationship between asymmetries and deterioration on physical performance [17]. So the influence of asymmetries on fatigue and the negative effects on exercise performance required more investigations.

Furthermore, there is an insufficiency of literature researching how side to side differences interact with physical performance between different chronological age groups. Read et al. [18] and Kellis et al. [19] examined different chronological age groups in youth male soccer players. Read et al. [18] showed that single-leg countermovement jump landing force asymmetry was significantly higher for circa and post-peak height velocity (PHV) $(p<0.001 ; \mathrm{d}=0.41-0.43)$ compared with those who were pre-PHV; whereas Kellis et al. [19] founded that asymmetry, during diverse strength parameters using a isokinetic dynamometry, was not affected by age. On the other hand, Bishop et al. [7] recently observed elite male soccer players (under (U-16 to U-23) and they founded that jump height of single leg $\mathrm{CMJ}$ was related with slower sprint and COD speed times $(\mathrm{r}=0.54-0.87)$. However, these studies have been executed in youth male soccer players, and to the authors' knowledge, no comparable data is available in adolescent female soccer players. Consequently, obtained results have not demonstrate conclusive findings when we try to determine the relation between inter-limb asymmetries and measures of physical performance, particularly in adolescent female soccer players.

Therefore, the objectives of this study were: (1) to measure inter-limb asymmetries in three distinct age groups in adolescent female soccer players, and (2) to determine the 
association between inter-limb asymmetries and measures of physical performance in different age groups.

\section{Materials and Methods}

\subsection{Participants}

Fifty-four adolescent female soccer players from three different teams of the same Spanish the club academy squad (Iberdrola Women's First Division) participated in this study. They were distributed in three age groups: U-18 $(n=18$; age: $16.9 \pm 0.5$ years; height $161.8 \pm 9.2 \mathrm{~cm}$; mass $57.7 \pm 9.3 \mathrm{~kg}), \mathrm{U}-16(n=21$; age: $14.9 \pm 0.5$ years; height $159.8 \pm 5.3 \mathrm{~cm}$; mass $53.6 \pm 8.1 \mathrm{~kg})$ and $\mathrm{U}-14(n=15$; age: $13.7 \pm 0.6$ years; height $154.1 \pm 7.9 \mathrm{~cm}$; mass $48.9 \pm 7.9 \mathrm{~kg}$ ). A priori power analysis identified that when aiming to assess differences between three independent groups at a statistical power of 0.8 , with an alpha level of 0.05 and effect size of $0.8,21$ players were required for each group. Thus, the present study is under-powered. However, it is worth noting that the present group were adolescent female and studies using such samples are likely to be under-powered given the limited number of athletes associated with this specific population. All the players have more than 4 years of training experience in soccer. The physical training sessions, in all teams, consisted of training exercises for coordination, agility, speed and injury prevention that allow maintaining the level of physical condition. Participants were healthy and without any disease or injury that could interfere with the study results. Informed consents were obtained from all players involved in this investigation. In accordance with the Declaration of Helsinki, the informed consents of all the players were obtained and the study was approved by the Ethical Committee for Clinical Research of the Government of Aragon (CP19/039, CEICA, Zaragoza, Spain).

\subsection{Procedures}

To ensure the standardized distribution of the groups, all the players followed the same protocols during the two sessions of physical tests. Do not participate in any strenuous exercise $24 \mathrm{~h}$ in advance. Do not take the last meal $3 \mathrm{~h}$ before the tests. Don't drink caffeinated beverages. The tests were performed at the same time of the day ( 6 p.m. to 8 p.m.). The first session was used to familiarize all participants with the jump, sprint and COD speed test. The second session, separated by $72 \mathrm{~h}$, the tests were carried out in a random and balanced order, for the correct data collection. The order of the tests was jump, sprint and COD speed test. These tests were performed by the same group of investigators, and were carried out on days with stable environmental conditions measured by a wet bulb globe temperature monitor $\left(\sim 22^{\circ} \mathrm{C}\right.$ and $\sim 20 \%$ humidity), days that did not comply with these environmental conditions were discarded, in an artificial grass soccer field where every team had their training sessions. All participants completed a rise, activate, mobilize and potentiate (RAMP) system warm-up protocol [20]. A 3-min rest period was provided after the last practice trial and the start of data collection. Three attempts per test were allowed with $3 \mathrm{~min}$ of passive recovery between repetitions. Players wore athletic shoes (for jump tests) and soccer boots (for linear sprint and COD test).

\subsection{Single Leg Countermovement Jump Test}

To calculate the vertical jump capacity, a single leg CMJ was used the Optojump tool (Optojump, Microgate, Bolzano, Italy). All subjects were instructed to perform a maximum vertical jump with their hands on their hips and to land in a vertical position with their knees bent, controlled and balanced, and held in the landing position for 2-3 s. Three attempts were made and the best jump was selected for analysis.

\subsection{Single Leg Hop Test}

To calculate single leg hop was used a standard measuring tape (30 m M13; Stanley, New Britain, CT, USA). Each subject started behind the starting line and jumped as far as possible (horizontal distance), landing on the same leg, controlled and balanced, and held 
in the landing position for $2-3 \mathrm{~s}$ [21]. Three attempts were made and the best jump was selected for analysis.

\subsection{0-m Sprint Test}

To calculate the running speed, it was recorded with photoelectric cells (Microgate). The sprint time of $40 \mathrm{~m}$, and the partial times of 10, 20 and $30 \mathrm{~m}$ were measured. Subjects like previous studies started with the front foot $0.5 \mathrm{~m}$ before the start [22]. The photoelectric cells were mounted on tripods $0.75 \mathrm{~m}$ above the ground and $3 \mathrm{~m}$ apart [23]. The test was prepared, and the player chose the moment of departure. The time began to count when the player cut the first photocell. Subjects were given verbal encouragement during each sprint. Three attempts were made and the best time was selected for analysis.

\section{6. $180^{\circ}$ Change of Direction Speed Test}

To calculate the $10-\mathrm{m}$ sprint test with a $180^{\circ} \mathrm{COD}$, it was recorded with photoelectric cells (Microgate). The $180^{\circ} \mathrm{COD}$ is a modification of the 505 test [24], with good test-retest reliability [25]. Subjects started with the front foot $0.5 \mathrm{~m}$ before the start. and a test was carried out at a maximum speed of $10 \mathrm{~m}$. plus $5 \mathrm{~m}$, turn $180^{\circ}$ on the right or left foot and $5 \mathrm{~m}$ to the finish line. The photoelectric cells were mounted on tripods $0.75 \mathrm{~m}$ above the ground and $3 \mathrm{~m}$ apart [23]. The test was prepared, and the player chose the moment of departure. The time began to count when the player cut the first photocell. Subjects were given verbal encouragement during each repetition. Three attempts were made and the best time was selected for analysis.

\subsection{Statistical Analysis}

All data were recorded as mean and standard deviation (SD). Normality was analyzed with the Shapiro-Wilk test and none of the variables had a normal distribution. Withinsession reliability of test measures was computed using a two-way random intraclass correlation coefficient (ICC) with absolute agreement and 95\% confidence intervals, and the coefficient of variation $(\mathrm{CV})$. The interpretation of the ICC values was excellent $(>0.90)$, good $(0.75-0.90)$, moderate $(0.5-0.75)$ and bad $(<0.50)[26]$ and as an acceptable criterion of responsibility a CV lower than $10 \%$ [27].

Noting that asymmetries may favour either side depending on which limb scores larger [4]. The consistency of the asymmetries was calculated with the Kappa coefficient and they were interpreted as poor $(\leq 0)$, mild $(0.01-0.20)$, regular $(0.21-0.40)$, moderate $(0.41-0.60)$, substantial $(0.61-0,80)$, almost perfect $(0.81-0.99)$ and perfect [28]. SPSS statistical software (Version 19.0; SPSS Inc, Chicago, IL, USA) was used.

Inter-limb asymmetries were quantified as the percentage difference between the two limbs using the following equation [29].

100/Max value (right and left) * Min value (right and left) * $-1+100$

A one-way analysis of variance was conducted to determine systematic bias between age groups for mean test scores and asymmetry values, with statistical significance set at $p<0.05$ identified via Bonferroni post-hoc analysis. The relationships between interlimb asymmetry scores and test scores were analysed using Spearman's $\rho$ correlations. To determine the magnitude of differences between the groups for each variable, effect sizes (ES) were calculated using standardized mean difference corrected as Hedges'g [30]. These were interpreted in line with Hopkins et al. [31] where trivial $(<0.2)$, small $(>0.2-0.6)$, moderate $(>0.6-1.2)$, large $(>1.2-2.0)$, very large $(>2.0-4.0)$ and near perfect $(>4.0)$.

\section{Results}

Table 1 shows the reliability within the session and shows high reliability except for COD of $180^{\circ}$ (ICC: $0.85-0.87$ ) and linear velocity of $10 \mathrm{~m}$ (ICC: 0.83 ), while acceptable CV was obtained for all tests $(<10 \%)$. 
Table 1. Mean test scores \pm standard deviation (SD) and reliability for all players.

\begin{tabular}{ccccc}
\hline Test & Mean \pm SD & \% Asymmetry & CV (\%) & ICC (95\% CI) \\
\hline $\mathrm{SLCMJ}_{\mathrm{R}}(\mathrm{cm})$ & $11.4 \pm 2.79$ & $11.6 \pm 7.54$ & 4.3 & $0.95(0.88 ; 0.98)$ \\
$\mathrm{SLCMJ}_{\mathrm{L}}(\mathrm{cm})$ & $11.3 \pm 3.05$ & & 5.8 & $0.95(0.87 ; 0.98)$ \\
$\mathrm{SLH}_{\mathrm{R}}(\mathrm{cm})$ & $120.9 \pm 15.9$ & $4.82 \pm 3.87$ & 2.8 & $0.96(0.89 ; 0.98)$ \\
$\mathrm{SLH}_{\mathrm{L}}(\mathrm{cm})$ & $121.1 \pm 12.6$ & & 2 & $0.93(0.82 ; 0.97)$ \\
$180^{\circ} \mathrm{COD}(\mathrm{s})$ & $3 \pm 0.14$ & $2.91 \pm 2.10$ & 1.4 & $0.87(0.69 ; 0.95)$ \\
$180^{\circ} \mathrm{COD}(\mathrm{s})$ & $3.01 \pm 0.16$ & - & 1.4 & $0.85(0.65 ; 0.94)$ \\
$10 \mathrm{~m}(\mathrm{~s})$ & $2.08 \pm 0.10$ & - & 1.8 & $0.83(0.62 ; 0.93)$ \\
$20 \mathrm{~m}(\mathrm{~s})$ & $3.61 \pm 0.17$ & - & 1.1 & $0.94(0.84 ; 0.97)$ \\
$30 \mathrm{~m}(\mathrm{~s})$ & $5.10 \pm 0.24$ & - & 0.6 & $0.98(0.95 ; 0.99)$ \\
$40 \mathrm{~m}(\mathrm{~s})$ & $6.64 \pm 0.34$ & & 0.6 & $0.98(0.96 ; 0.99)$ \\
\hline
\end{tabular}

Note: SLCMJ: Single leg countermovement jump; SLH: Single leg hop test; $180^{\circ}$ COD: $5+5$ sprint test with a $180^{\circ}$ change of direction; L: Left; R: Right; CV: Coefficient of variation; ICC: Intraclass correlation coefficient; CI: Confidence intervals.

Mean test scores and ES for each group are presented in Table 2. The U-18 group performed significantly better jumps and faster times than the U-14 in single leg hop test left and $180^{\circ}$ COD left. The U-16 group were significantly faster than the U-14 over 40-m and $180^{\circ} \mathrm{COD}$ left. No other significant differences between groups were found.

Table 2. Mean data \pm standard deviation for each age group and effect sizes between groups.

\begin{tabular}{|c|c|c|c|c|c|c|}
\hline Test & U-18 & U-16 & U-14 & ES U-18 vs. U-16 & ES U-18 vs. U-14 & ES U-16 vs. U-14 \\
\hline $\mathrm{SLCMJ}_{R}(\mathrm{~cm})$ & $11.9 \pm 2.6$ & $11.7 \pm 3.08$ & $10.4 \pm 2.34$ & -0.07 (trivial) & -0.57 (small) & -0.51 (small) \\
\hline $\operatorname{SLCMJ}_{\mathrm{L}}(\mathrm{cm})$ & $11.9 \pm 3.2$ & $11.8 \pm 2.86$ & $10.1 \pm 2.77$ & 0.02 (trivial) & -0.66 (moderate) & -0.76 (moderate) \\
\hline As CMJ (\%) & $10.9 \pm 5.96$ & $11.6 \pm 8.47$ & $12.1 \pm 8.34$ & 0.09 (trivial) & 0.16 (trivial) & 0.05 (trivial) \\
\hline $\mathrm{SLH}_{\mathrm{R}}(\mathrm{cm})$ & $123.1 \pm 12.6$ & $123.6 \pm 18.6$ & $113.7 \pm 10.2$ & 0.11 (trivial) & -0.63 (moderate) & - 0.74 (moderate) \\
\hline $\mathrm{SLH}_{\mathrm{L}}(\mathrm{cm})$ & $124.1 \pm 3.6^{*}$ & $123.1 \pm 13.5$ & $114.5 \pm 8.95$ & 0.04 (trivial) & -0.72 (moderate) & -0.90 (moderate) \\
\hline As SLH (\%) & $3.68 \pm 3.01$ & $5.11 \pm 4.19$ & $5.77 \pm 4.19$ & 0.04 (trivial) & 0.57 (small) & 0.15 (trivial) \\
\hline $180^{\circ} \mathrm{COD}_{\mathrm{R}}(\mathrm{s})$ & $2.96 \pm 0.14$ & $2.99 \pm 0.14$ & $3.07 \pm 0.13$ & -0.03 (trivial) & 0.40 (small) & 0.90 (moderate) \\
\hline $180^{\circ} \mathrm{COD}_{\mathrm{L}}(\mathrm{s})$ & $2.95 \pm 0.14$ * & $2.98 \pm 0.13^{* *}$ & $3.12 \pm 0.15$ & -0.01 (trivial) & 0.80 (moderate) & 0.74 (moderate) \\
\hline As COD $(\%)$ & $2.57 \pm 1.77$ & $2.91 \pm 2.31$ & $3.32 \pm 2.20$ & 0.16 (trivial) & 0.37 (small) & 0.17 (trivial) \\
\hline $10 \mathrm{~m}(\mathrm{~s})$ & $2.05 \pm 0.10$ & $2.08 \pm 0.10$ & $2.12 \pm 0.10$ & -0.29 (small) & 0.23 (small) & 0.69 (moderate) \\
\hline $20 \mathrm{~m}(\mathrm{~s})$ & $3.57 \pm 0.17$ & $3.63 \pm 0.17$ & $3.66 \pm 0.14$ & -0.32 (small) & 0.72 (moderate) & 1.13 (moderate) \\
\hline $30 \mathrm{~m}(\mathrm{~s})$ & $5.04 \pm 0.25$ & $5.12 \pm 025$ & $5.16 \pm 0.20$ & -0.32 (small) & 0.60 (moderate) & 0.48 (small) \\
\hline $40 \mathrm{~m}(\mathrm{~s})$ & $6.53 \pm 0.34$ & $6.62 \pm 0.34^{* *}$ & $6.84 \pm 0.26$ & -0.27 (small) & 1.03 (moderate) & 0.87 (moderate) \\
\hline
\end{tabular}

Note: SLCMJ: Single leg countermovement jump; SLH: Single leg hop test; $180^{\circ}$ COD: $5+5$ sprint test with a $180^{\circ}$ change of direction; L: Left; R: Right; ES: Effect size. U-18: Under 18; U-16: Under 16; U-14: Under 14. * Significant difference $(p<0.05)$ between U-18 and U-14 players. ${ }^{* *}$ Significant difference $(p<0.05)$ between $U-16$ and $U-14$ players.

When comparing ES, trivial to moderate differences were evident between all group comparisons. Table 3 shows the levels of agreement for the asymmetry scores (Kappa coefficient).

The results showed substantial levels of agreement of U-16 between single leg CMJ and single leg hop test (0.45). The rest of the groups show poor to fair levels (range: -0.31 to 0.24 ) for all comparisons. Owing to the variable nature in both the magnitude and direction of asymmetry, individual inter-limb differences are presented for jump and COD speed tests in U-14 (Figure 1), U-16 (Figure 2) and U-18 (Figure 3) female soccer player. 
Table 3. Kappa coefficients and descriptive levels of concordance of asymmetries between the jumping speed and COD tests.

\begin{tabular}{lcc}
\hline \multicolumn{1}{c}{ Test Comparison } & Kappa Coefficient & Descriptor \\
\hline Under-14: & & \\
SLCMJ- SLH & 0.13 & Slight \\
SLCMJ-180 COD & -0.13 & Poor \\
SLH-180 COD & -0.31 & Poor \\
\hline Under-16: & & \\
SLCMJ-SLH & 0.45 & Moderate \\
SLCMJ-180 COD & -0.03 & Poor \\
SLH-180 COD & -0.03 & Poor \\
\hline Under-18: & & \\
SLCMJ- SLH & -0.16 & Poor \\
SLCMJ-180 COD & 0.24 & Fair \\
SLH-180 COD & 0.10 & Fair \\
\hline
\end{tabular}

Note: SLCMJ: Single leg countermovement jump; SLH: Single leg hop test; $180^{\circ}$ COD: $5+5$ sprint test with a $180^{\circ}$ change of direction.

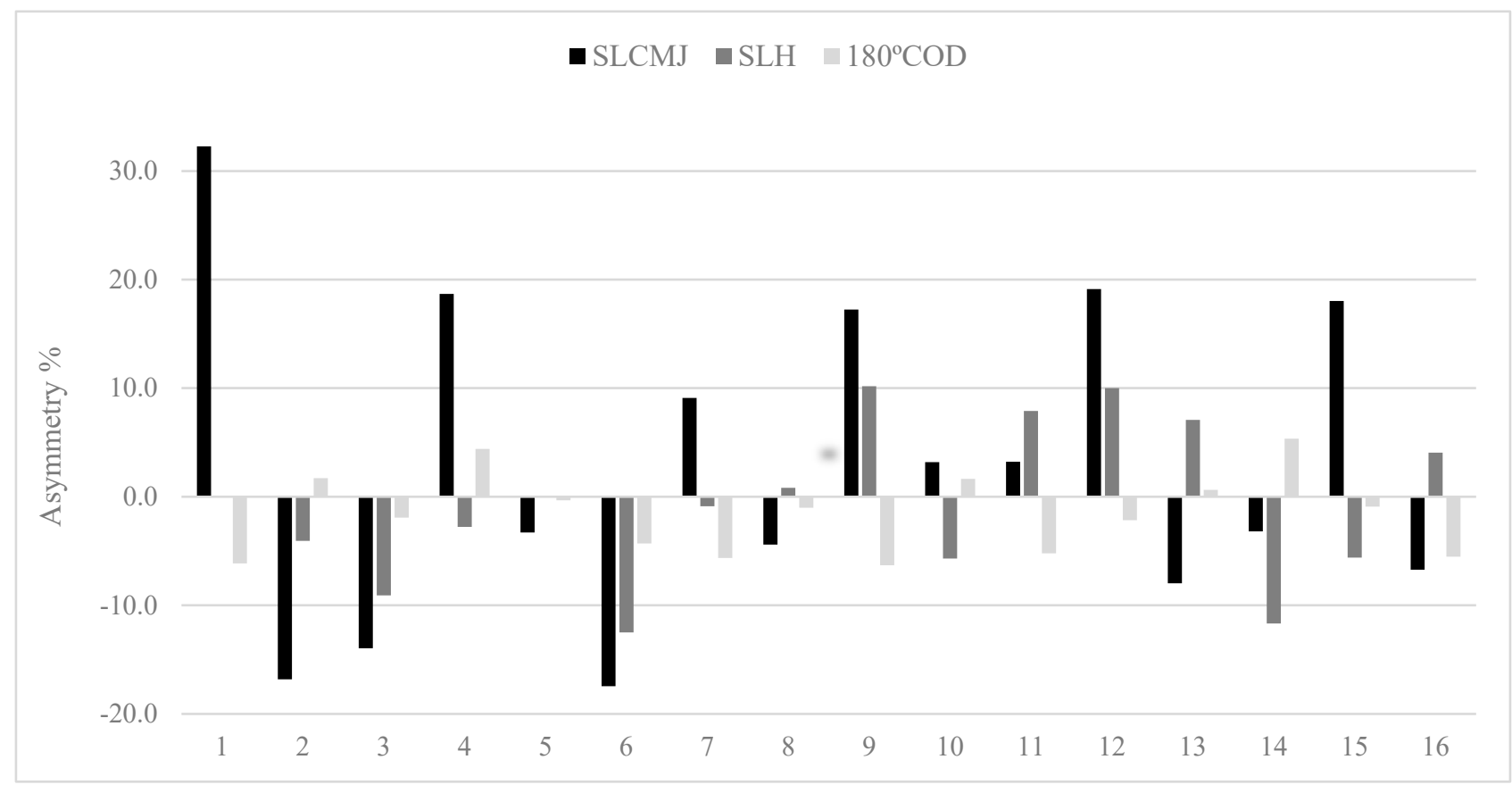

Figure 1. Data about individual asymmetry for single leg countermovement jump (SLCMJ), single leg hop (SLH) and $180^{\circ}$ change of direction $\left(180^{\circ} \mathrm{COD}\right)$ in the U-14 group. N.B: above 0 indicates right leg dominance and below 0 indicates left leg dominance.

Table 4 shows Spearman's $\rho$ correlations between vertical and horizontal inter-limb asymmetry scores and tests data. No significant relationships were present between single leg CMJ and single leg hop inter-limb asymmetry scores and sprint or COD speed performance. Spearman's $\rho$ correlations between COD speed inter-limb asymmetry scores and tests are shown in Table 5. No significant relationships were found between COD speed inter-limb asymmetry scores and sprint or jump performance. 


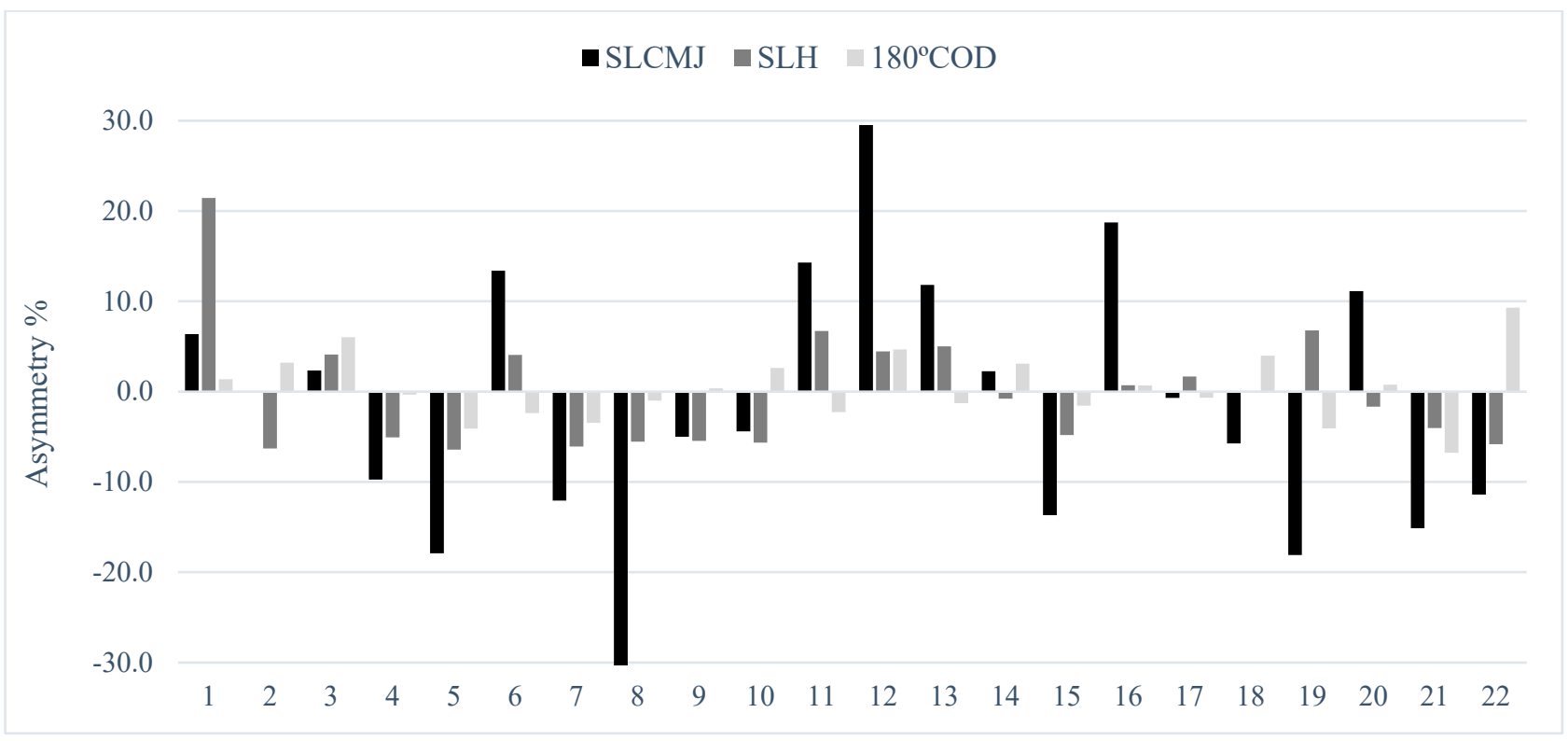

Figure 2. Data about individual asymmetry for single leg countermovement jump (SLCMJ), single leg hop (SLH) and $180^{\circ}$ change of direction $\left(180^{\circ} \mathrm{COD}\right)$ in the U-16 group. N.B: above 0 indicates right leg dominance and below 0 indicates left leg dominance.

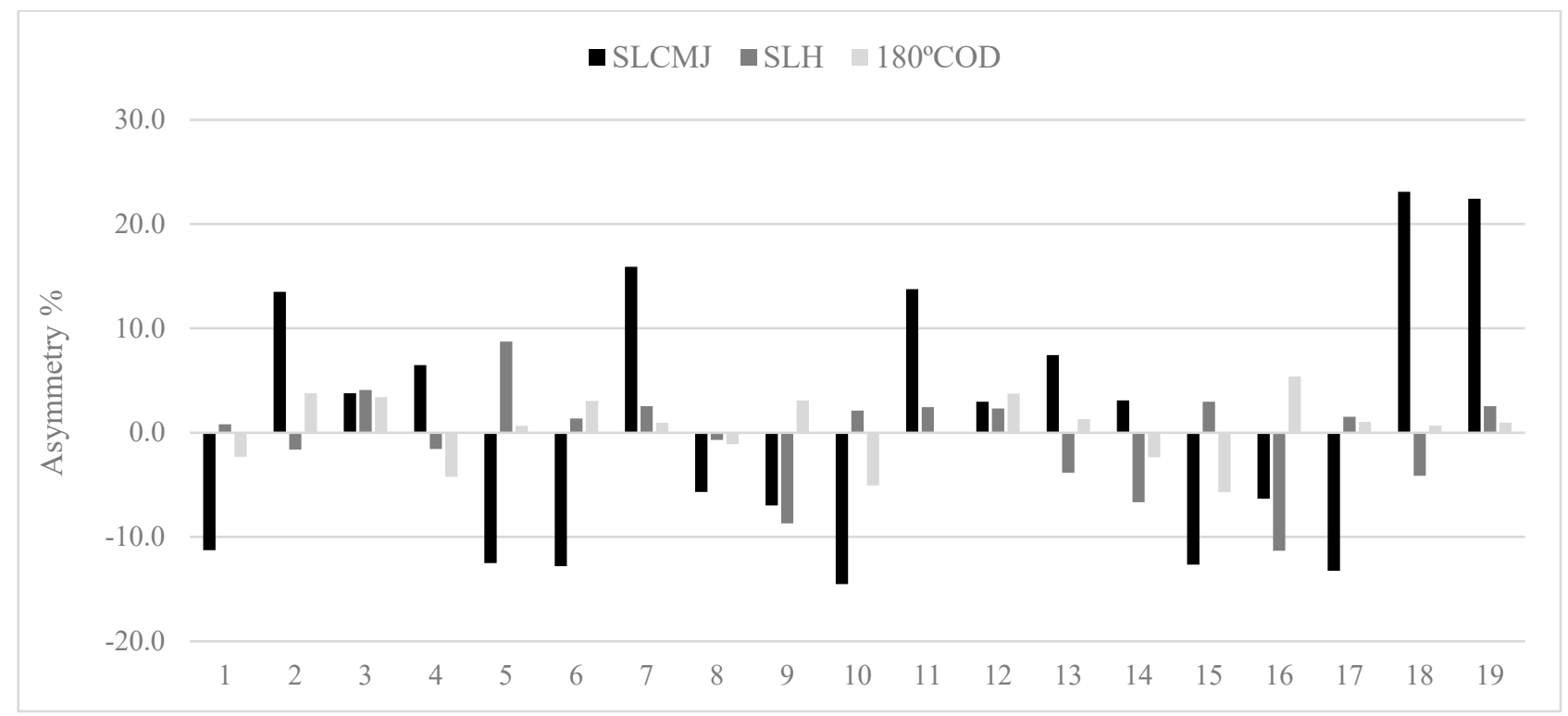

Figure 3. Data about individual asymmetry for single leg countermovement jump (SLCMJ), single leg hop (SLH) and $180^{\circ}$ change of direction $\left(180^{\circ} \mathrm{COD}\right)$ in the U-18 group. N.B: above 0 indicates right leg dominance and below 0 indicates left leg dominance. 
Table 4. Spearman's $\rho$ correlation between vertical and horizontal jump height asymmetry and test across age groups.

\begin{tabular}{ccccccc}
\hline \multirow{2}{*}{ Test } & \multicolumn{3}{c}{ Asymmetry SLCMJ } & \multicolumn{3}{c}{ Asymmetry SLH } \\
\cline { 2 - 6 } & $\mathbf{U - 1 4}$ & $\mathbf{U - 1 6}$ & $\mathbf{U - 1 8}$ & $\mathbf{U - 1 4}$ & $\mathbf{U - 1 6}$ & U-18 \\
\hline $180^{\circ} \mathrm{COD}_{\mathrm{R}}(\mathrm{s})$ & -0.11 & -0.16 & -0.26 & 0.44 & -0.06 & 0.50 \\
$180^{\circ} \mathrm{COD}_{\mathrm{L}}(\mathrm{s})$ & 0.11 & 0.06 & -0.36 & 0.35 & -0.01 & 0.25 \\
$10 \mathrm{~m}(\mathrm{~s})$ & -0.25 & -0.05 & -0.06 & -0.06 & -0.32 & 0.25 \\
$20 \mathrm{~m}(\mathrm{~s})$ & -0.17 & 0.05 & 0.00 & 0.07 & -0.34 & 0.25 \\
$30 \mathrm{~m}(\mathrm{~s})$ & -0.21 & 0.07 & 0.09 & 0.04 & -0.33 & 0.26 \\
$40 \mathrm{~m}(\mathrm{~s})$ & 0.10 & 0.10 & 0.12 & -0.06 & -0.33 & 0.22 \\
\hline
\end{tabular}

Note: SLCMJ: Single leg countermovement jump; SLH: Single leg hop test; $180^{\circ}$ COD: $5+5$ sprint test with a $180^{\circ}$ change of direction; L: Left; R: Right; U-18: Under 18; U-16: Under 16; U-14: Under 14.

Table 5. Spearman's $\rho$ correlation between change of direction (COD) speed asymmetry and test across age groups.

\begin{tabular}{cccc}
\hline \multirow{2}{*}{ Test } & \multicolumn{3}{c}{ Asymmetry COD Speed } \\
\cline { 2 - 4 } & $\mathbf{U - 1 4}$ & $\mathbf{U}-\mathbf{1 6}$ & $\mathbf{U - 1 8}$ \\
\hline SLCMJ $_{\mathrm{R}}(\mathrm{cm})$ & -0.01 & -0.27 & -0.32 \\
SLCMJ $_{\mathrm{L}}(\mathrm{cm})$ & -0.01 & -0.01 & -0.14 \\
SLH $_{\mathrm{R}}(\mathrm{cm})$ & -0.16 & -0.49 & -0.16 \\
SLH $_{\mathrm{L}}(\mathrm{cm})$ & -0.48 & -0.39 & -0.09 \\
$10 \mathrm{~m}(\mathrm{~s})$ & 0.48 & 0.24 & 0.35 \\
20 m (s) & 0.51 & 0.25 & 0.25 \\
$30 \mathrm{~m}(\mathrm{~s})$ & 0.45 & 0.26 & 0.16 \\
$40 \mathrm{~m}(\mathrm{~s})$ & 0.49 & 0.26 & 0.12 \\
\hline
\end{tabular}

Note: SLCMJ: Single leg countermovement jump; SLH: Single leg hop test; $180^{\circ}$ COD: $5+5$ sprint test with a $180^{\circ}$ change of direction; L: Left; R: Right; U-18: Under 18; U-16: Under 16; U-14: Under 14.

\section{Discussion}

The objectives of this study were to establish inter-limb asymmetry scores from the single leg CMJ, single leg hop test and $180^{\circ}$ COD speed in adolescent female soccer players across different age groups, and to determine the relationship between these asymmetries and measures of physical performance. Outcomes demonstrated different magnitudes of asymmetry between tests. Vertical jump test showed larger asymmetry scores when comparing to horizontal jump test and COD speed test. There were no meaningful relationships between asymmetry scores and independent measures of physical performance. Moreover, asymmetries rarely favored the same side between jump and COD speed tests, highlighting the task-specific nature of inter-limb differences.

The totally of tests showed an exceptional relative reliability and an acceptable variability, and this can indicate that the results can be understood with confidence for next analysis [32]. The experience and the regular strength and conditioning training performed during the season may provide to the acceptable reliability of the data [33]. In relation to the asymmetry scores reported in the present study, the COD speed test $(2.9 \%)$ showed a lower magnitude of asymmetry in comparison to the single leg CMJ test $(11.6 \%)$, this is in contract with previous research [10,34]. Asymmetry is highly task-specific and although some tests produce larger asymmetry values, the inherent variability in asymmetry scores is still large for all tests, as shown by the varying magnitude of asymmetry at an individual level (see Figures 1-3). For this reason, it is advisable that researchers, coaches and practitioners calculate not only result measures (e.g., jump height and reactive strength index) but also test variability [10]. This will enable practitioners to determine when asymmetries are 'real' (i.e., greater than the test error) or within the measured noise of the test [8].

An outstanding point to take into account from these results is that vertical jump (single leg CMJ: $11.6 \%$ ) showed greater asymmetries than horizontal jump (single leg hop test: $4.8 \%$ ), and this is in agreement with previous research [6,35]. In the same line, 
Bishop et al. [6] showed asymmetries of $12.5 \%$ and $6.8 \%$ in single leg CMJ and single leg hop test respectively, in elite youth female soccer players. It is possible that vertical jump may be more sensitive at identifying asymmetries because in these cases the study population are adolescent players. Children exercise horizontal hopping activities (e.g., hopscotch and somersault) from an early age [36,37]. These horizontal movement patterns are performed more than unilateral vertical tasks [6]. This can clarify the reason why inter-limb differences are not as horizontal jump, notwithstanding, more researches are still necessary to completely support this theory.

No significant differences between groups were during the asymmetry of CMJ, single leg hop and COD tests (Table 2). Intuitively, given the physical maturity of older athletes in comparison with younger, it seems logical to assume that these players would be able to be better asymmetry scores. In addition, there is a tendency for females' athletic performance to reach a plateau around the age of 13 years (puberty) [38], for this reason may be better asymmetry parameters in the older female groups in our study. This is supported in previous research by several studies which showed that older players outperformed younger players on jump and COD speed asymmetries [6,13,39-41].

The Kappa coefficient (Table 3) was calculated for the purpose of determining how usually asymmetries favoured the same side between tests. Results showed poor to fair levels of agreement for the side consistency of asymmetry between jumps and COD speed (Kappa range $=-0.31$ to 0.45 ). Simply put, if an asymmetry was favoured on the left limb during one of the jump tests, it was unlikely that the same side performed superiorly during the COD speed test. Previous research showed very low levels of agreement $(<0.2)$ between different tests, indicating that asymmetries for these metrics favoured the imbalance $[4,42]$. In contrast, a comparison between both jumps in U-16 players showed moderate levels of agreement (Kappa: 0.45), corroborating that these asymmetries were more frequently present on the same side. The noticeably better levels of agreement between single leg $\mathrm{CMJ}$ and single leg hop test shows that these two tests shared some similarities in limb dominance, regardless of whether the focus was maximal jump height or distance. These results are partly in accordance with Bishop et al. [39] who showed a substantial level of agreement (Kappa: 0.61) between the squat jump and CMJ, in youth female soccer players. Consequently, these results demonstrate the variable nature of magnitude and direction of asymmetry and emphasize the require for more individual approach to data analysis [4] (Figures 1-3).

In Table 1 we have observed that inter-limb asymmetry metrics vary depend on the test used, and for this reason it is evident that not all female players react similarly to the same test referring to asymmetry. In this regard, group mean asymmetry scores ranged from 2.91 to $11.6 \%$; however, many individual asymmetry values exceeded these percentages, mainly in vertical jump test (Figures 1-3). Literature has shown that asymmetries of $>10 \%$ may decrease jump height [43] and increase COD speed times [44] indicating that the reduction of these differences may be favourable. Moreover, the direction of asymmetry to favour the left limb was observed in our results (i.e., non-dominant kicking limb) [10], in this case, $31-68 \%$ female players presented asymmetry on the left side for jump and COD speed tests. For these reasons, the individual information seems to be important to design a precise training program, with a view to reduce inter-limb asymmetries and therefore, to improve athletic performance and to decrease potential risk of injury $[8,45]$. In addition, other interesting methods for evaluating asymmetries could be used such us the Functional Movement Screen, ankle dorsiflexion or Y Balance test $[40,46]$. However, the problem to evaluate asymmetry from these tests, is that it is subjective interpretation of human movement quality [47]. Asymmetry is already a very noisy and variable concept, so to include subjective data could add more error to the equation.

There are no relevant relation between asymmetry results, emphasizing the independent nature of jumping, sprinting and COD speed test in adolescent female soccer players (Tables 3 and 4). This finding is supported by preceding studies $[10,11]$, which do not observe any correlation between different asymmetry results in female soccer players. 
Moreover, Bishop et al. [48] observed in a recent literature that comparing asymmetry scores over multiple tests levels of agreement were often poor (i.e., Kappa Coefficients $<0$ ). Put simply, this indicates that the direction of asymmetry is rarely the same between tasks and provides further evidence of the task-specific nature of measuring side-to-side differences [49]. This highlights that if profiling asymmetry is deemed necessary, practitioners should do so using a variety of tests and not expect the same outcome between them. Furthermore, despite previous research in a comparable sample also showing no significant associations between asymmetry and independent measures of performance [11], the variable nature of asymmetry is undoubtedly a key factor in the lack of significant relationships with independent measures of athletic performance.

In this regard, it has been suggested to locate possible bilateral differences and imbalances between limbs is necessary to performed more than one type of exercise [42,50]. In addition, inter-limb asymmetries can also influence performance (e.g., greater symmetrical team-sports players look like they are faster than their asymmetrical counterparts) [35]. In this respect, strength and plyometric training are two of the most often used strategies to enhance soccer performance and high-intensity actions, just like decreasing asymmetries $[40,41,51]$. Therefore, adolescent female soccer players should make strength and plyometric exercises to improve performance and also, to reduce asymmetries.

In spite of the utility of these findings, the present study has several restrictions which must be recognized. Adolescent female soccer players have specific characteristics (e.g., anthropometry) and, so our outcomes cannot be extrapolated to other sports. Information on participation in other sports was not collected in the current sample. There were no differences in playing position due to the limited number of players presented in every single playing role. Consequently, we strongly recommend that future studies be conducted with the wider statistical population, collecting information about participation in other sports and considering more players for each playing positions. In addition, practitioners working in soccer may wish to consider defining limbs as 'dominant' and 'non-dominant', in respect to the preferred kicking limb; not as right and left, as in the present study. However, it is worth noting that this method does not always guarantee that the dominant limb will be the superior performing limb [10,52]. With that in mind, if limbs are defined within the context of dominance, close attention to the raw test scores (not just asymmetry) is required, so that the weaker or under-performing limb can be accurately identified. With this information, practitioners can accurately determine whether targeted training interventions are required.

\section{Conclusions}

In conclusion, jumping and COD physical tests show asymmetries in adolescent female soccer players, but these asymmetries do not interfere with their physical performance. The largest asymmetry was observed in the single leg countermovement jump, and no asymmetries between groups (U-18, U-16 and U-14) were found. Finally, the direction of asymmetry appears highly variable, so the individual analysis of asymmetries should be consider to perform more precise training interventions on an individual level.

Author Contributions: For research articles with several authors, a short paragraph specifying their individual contributions must be provided. The following statements should be used "Conceptualization, E.P.-M. and C.B.; methodology, E.P.-M. and C.B.; software, E.P.-M. and C.B.; validation, E.P.-M., C.B., O.G.-S., J.P.-G., and D.L.; formal analysis, E.P.-M. and C.B.; investigation, E.P.-M., O.G.-S., and C.B.; resources, E.P.-M., D.L. and C.B.; data curation, E.P.-M., J.P.-G. and C.B.; writing-original draft preparation, E.P.-M. and C.B.; writing-review and editing, O.G.-S., H.N., J.P.-G., and D.L.; visualization, E.P.-M., and D.L.; supervision, E.P.-M., H.N. and D.L.; project administration, E.P.-M. and D.L. All authors have read and agreed to the published version of the manuscript.

Funding: This research received no external funding. 
Institutional Review Board Statement: The study was conducted according to the Declaration of Helsinki and was approved by the Ethics Committee of Clinical Research from the Government of Aragón (CP19/039, CEICA, Spain).

Informed Consent Statement: Informed consent was obtained from all subjects involved in the study.

Data Availability Statement: The datasets generated and analyzed for this study can be requested by correspondence authors in epardos@usj.es and dlozano@usj.es.

Conflicts of Interest: The authors declare no conflict of interest.

\section{References}

1. FIFA. Women's Football Survey. 2014. Available online: https://img.fifa.com/image/upload/emtgxvp0ibnebltlvi3b.pdf (accessed on 18 August 2020).

2. Čović, N.; Jelešković, E.; Alić, H.; Rađo, I.; Kafedžić, E.; Sporiš, G.; McMaster, D.T.; Milanović, Z. Reliability, Validity and Usefulness of 30-15 Intermittent Fitness Test in Female Soccer Players. Front. Physiol. 2016, 7, 510. [CrossRef] [PubMed]

3. Gonzalo-Skok, O.; Tous-Fajardo, J.; Suarez-Arrones, L.; Arjol-Serrano, J.L.; Casajús, J.A.; Mendez-Villanueva, A. Single-Leg Power Output and Between-Limbs Imbalances in Team-Sport Players: Unilateral Versus Bilateral Combined Resistance Training. Int. J. Sports Physiol. Perform. 2017, 12, 106-114. [CrossRef] [PubMed]

4. Bishop, C.; Lake, J.; Loturco, I.; Papadopoulos, K.; Turner, A.; Read, P. Interlimb Asymmetries: The Need for an Individual Approach to Data Analysis. J. Strength Cond. Res. 2021, 35, 695-701. [CrossRef] [PubMed]

5. Keeley, D.W.; Plummer, H.A.; Oliver, G.D. Predicting Asymmetrical Lower Extremity Strength Deficits in College-Aged Men and Women Using Common Horizontal and Vertical Power Field Tests: A Possible Screening Mechanism. J. Strength Cond. Res. 2011, 25, 1632-1637. [CrossRef]

6. Bishop, C.; Read, P.; McCubbine, J.; Turner, A. Vertical and Horizontal Asymmetries Are Related to Slower Sprinting and Jump Performance in Elite Youth Female Soccer Players. J. Strength Cond. Res. 2021, 35, 56-63. [CrossRef] [PubMed]

7. Bishop, C.; Brashill, C.; Abbott, W.; Read, P.; Lake, J.; Turner, A. Jumping Asymmetries Are Associated with Speed, Change of Direction Speed, and Jump Performance in Elite Academy Soccer Players. J. Strength Cond. Res. 2019. [CrossRef]

8. Bishop, C.; Turner, A.; Read, P. Effects of inter-limb asymmetries on physical and sports performance: A systematic review. J. Sports Sci. 2018, 36, 1135-1144. [CrossRef] [PubMed]

9. Hart, N.H.; Nimphius, S.; Weber, J.; Spiteri, T.; Rantalainen, T.; Dobbin, M.; Newton, R.U. Musculoskeletal Asymmetry in Football Athletes: A Product of Limb Function over Time. Med. Sci. Sports Exerc. 2016, 48, 1379-1387. [CrossRef] [PubMed]

10. Bishop, C.; Turner, A.; Maloney, S.; Lake, J.; LoTurco, I.; Bromley, T.; Read, P. Drop Jump Asymmetry is Associated with Reduced Sprint and Change-of-Direction Speed Performance in Adult Female Soccer Players. Sports 2019, 7, 29. [CrossRef]

11. LoTurco, I.; Pereira, L.A.; Kobal, R.; Abad, C.C.C.; Rosseti, M.; Carpes, F.P.; Bishop, C. Do asymmetry scores influence speed and power performance in elite female soccer players? Biol. Sport 2019, 36, 209-216. [CrossRef] [PubMed]

12. Heil, J.; Loffing, F.; Büsch, D. The Influence of Exercise-Induced Fatigue on Inter-Limb Asymmetries: A Systematic Review. Sports Med. Open 2020, 6, 1-16. [CrossRef] [PubMed]

13. Raya-González, J.; Clemente, F.M.; Castillo, D. Analyzing the Magnitude of Interlimb Asymmetries in Young Female Soccer Players: A Preliminary Study. Int. J. Environ. Res. Public Health 2021, 18, 475. [CrossRef] [PubMed]

14. Bishop, C.; McAuley, W.; Read, P.; Gonzalo-Skok, O.; Lake, J.; Turner, A. Acute Effect of Repeated Sprints on Interlimb Asymmetries During Unilateral Jumping. J. Strength Cond. Res. 2019. [CrossRef] [PubMed]

15. Fort-Vanmeerhaeghe, A.; Milà-Villarroel, R.; Pujol-Marzo, M.; Arboix-Alió, J.; Bishop, C. Higher Vertical Jumping Asymmetries and Lower Physical Performance are Indicators of Increased Injury Incidence in Youth Team-Sport Athletes. J. Strength Cond. Res. 2020. [CrossRef] [PubMed]

16. Fort-Vanmeerhaeghe, A.; Bishop, C.; Buscà, B.; Aguilera-Castells, J.; Vicens-Bordas, J.; Gonzalo-Skok, O. Inter-limb asymmetries are associated with decrements in physical performance in youth elite team sports athletes. PLoS ONE 2020, 15, e0229440. [CrossRef]

17. Maloney, S.J. The Relationship Between Asymmetry and Athletic Performance: A Critical Review. J. Strength Cond. Res. 2019, 33, 2579-2593. [CrossRef]

18. Read, P.J.; Oliver, J.L.; Myer, G.D.; De Ste Croix, M.B.; Lloyd, R.S. The Effects of Maturation on Measures of Asymmetry During Neuromuscular Control Tests in Elite Male Youth Soccer Players. Pediatr. Exerc. Sci. 2018, 30, 168-175. [CrossRef]

19. Kellis, S.; Gerodimos, V.; Kellis, E.; Manou, V. Bilateral isokinetic concentric and eccentric strength profiles of the knee extensors and flexors in young soccer players. Isokinet. Exerc. Sci. 2001, 9, 31-39. [CrossRef]

20. Jeffreys, I. Warm up Revisited-The “Ramp" Method of Optimising Performance Preparation. Available online: https://www. uksca.org.uk/assets/pdfs/UkscaIqPdfs/ramp-warmups-more-than-simply-shortterm-preparation-636825390373342631.pdf (accessed on 27 March 2021).

21. Munro, A.G.; Herrington, L.C. Between-Session Reliability of Four Hop Tests and the Agility T-Test. J. Strength Cond. Res. 2011, 25, 1470-1477. [CrossRef] 
22. Nobari, H.; Silva, A.F.; Clemente, F.M.; Siahkouhian, M.; García-Gordillo, M. Ángel; Adsuar, J.C.; Pérez-Gómez, J. Analysis of Fitness Status Variations of Under-16 Soccer Players Over a Season and Their Relationships with Maturational Status and Training Load. Front. Physiol. 2021, 11, 597697. [CrossRef]

23. Nobari, H.; Polito, L.F.T.; Clemente, F.M.; Pérez-Gómez, J.; Ahmadi, M.; Garcia-Gordillo, M.A.; Silva, A.F.; Adsuar, J.C. Relationships Between Training Workload Parameters with Variations in Anaerobic Power and Change of Direction Status in Elite Youth Soccer Players. Int. J. Environ. Res. Public Health 2020, 17, 7934. [CrossRef] [PubMed]

24. Draper, J.A. The 505 test: A test for agility in horizontal plane. Aust. J. Sci. Med. Sport 1985, 17, 15-18.

25. Pardos-Mainer, E.; Casajús, J.A.; Gonzalo-Skok, O. Reliability and sensitivity of jumping, linear sprinting and change of direction ability tests in adolescent female football players. Sci. Med. Footb. 2018, 3, 183-190. [CrossRef]

26. Koo, T.K.; Li, M.Y. A Guideline of Selecting and Reporting Intraclass Correlation Coefficients for Reliability Research. J. Chiropr. Med. 2016, 15, 155-163. [CrossRef] [PubMed]

27. Cormack, S.J.; Newton, R.U.; McGuigan, M.R.; Doyle, T.L. Reliability of Measures Obtained During Single and Repeated Countermovement Jumps. Int. J. Sports Physiol. Perform. 2008, 3, 131-144. [CrossRef] [PubMed]

28. Viera, A.J.; Garrett, J.M. Understanding interobserver agreement: The kappa statistic. Fam. Med. 2005, 37, 360-363. [PubMed]

29. Bishop, C.; Read, P.; Lake, J.; Chavda, S.; Turner, A. Interlimb Asymmetries: Understanding How to Calculate Differences FROM Bilateral and Unilateral Tests. Strength Cond. J. 2018, 40, 1-6. [CrossRef]

30. Lakens, D. Calculating and reporting effect sizes to facilitate cumulative science: A practical primer for t-tests and ANOVAs. Front. Psychol. 2013, 4, 863. [CrossRef]

31. Hopkins, W.G.; Marshall, S.W.; Batterham, A.M.; Hanin, J. Progressive Statistics for Studies in Sports Medicine and Exercise Science. Med. Sci. Sports Exerc. 2009, 41, 3-13. [CrossRef]

32. Turner, A.; Brazier, J.; Bishop, C.; Chavda, S.; Cree, J.; Read, P. Data Analysis for Strength and Conditioning Coaches: Using excel to analyse reliability, differences, and relationships. Strength Cond. J. 2015, 37, 76-83. [CrossRef]

33. Bishop, C.; Berney, J.; Lake, J.; Loturco, I.; Blagrove, R.; Turner, A.; Read, P. Bilateral deficit during jumping tasks: Relationship with speed and change of direction speed performance. J. Strength Cond. Res. 2019. [CrossRef] [PubMed]

34. Madruga-Parera, M.; Bishop, C.; Fort-Vanmeerhaeghe, A.; Beltran-Valls, M.R.; Skok, O.G.; Romero-Rodríguez, D. Interlimb Asymmetries in Youth Tennis Players: Relationships with Performance. J. Strength Cond. Res. 2020, 34, 2815-2823. [CrossRef] [PubMed]

35. Lockie, R.G.; Callaghan, S.J.; Berry, S.P.; Cooke, E.R.A.; Jordan, C.A.; Luczo, T.M.; Jeffriess, M.D. Relationship Between Unilateral Jumping Ability and Asymmetry on Multidirectional Speed in Team-Sport Athletes. J. Strength Cond. Res. 2014, 28, 3557-3566. [CrossRef]

36. Ridgers, N.D.; Stratton, G.; Fairclough, S.J.; Twisk, J.W.R. Children's physical activity levels during school recess: A quasiexperimental intervention study. Int. J. Behav. Nutr. Phys. Act. 2007, 4, 1-9. [CrossRef]

37. Wake, M.; Lycett, K.; Clifford, S.A.; Sabin, M.A.; Gunn, J.; Gibbons, K.; Hutton, C.; McCallum, Z.; Arnup, S.J.; Wittert, G. Shared care obesity management in 3-10 year old children: 12 month outcomes of HopSCOTCH randomised trial. BMJ 2013, $346, \mathrm{f} 3092$. [CrossRef]

38. Rogol, A.D.; Clark, P.A.; Roemmich, J.N. Growth and pubertal development in children and adolescents: Effects of diet and physical activity. Am. J. Clin. Nutr. 2000, 72, 521S-528S. [CrossRef]

39. Bishop, C.; Pereira, L.A.; Reis, V.P.; Read, P.; Turner, A.N.; LoTurco, I. Comparing the magnitude and direction of asymmetry during the squat, countermovement and drop jump tests in elite youth female soccer players. J. Sports Sci. 2020, 38, 1296-1303. [CrossRef] [PubMed]

40. Pardos-Mainer, E.; Casajús, J.A.; Gonzalo-Skok, O. Adolescent female soccer players' soccer-specific warm-up effects on performance and inter-limb asymmetries. Biol. Sport 2019, 36, 199-207. [CrossRef]

41. Pardos-Mainer, E.; Casajús, J.A.; Bishop, C.; Gonzalo-Skok, O. Effects of Combined Strength and Power Training on Physical Performance and Interlimb Asymmetries in Adolescent Female Soccer Players. Int. J. Sports Physiol. Perform. 2020, 15, 1-9. [CrossRef]

42. LoTurco, I.; Pereira, L.A.; Kobal, R.; Abad, C.C.C.; Komatsu, W.; Cunha, R.; Arliani, G.; Ejnisman, B.; Pochini, A.D.C.; Nakamura, F.Y.; et al. Functional Screening Tests: Interrelationships and Ability to Predict Vertical Jump Performance. Int. J. Sports Med. 2017, 39, 189-197. [CrossRef] [PubMed]

43. Bell, D.R.; Sanfilippo, J.L.; Binkley, N.; Heiderscheit, B.C. Lean Mass Asymmetry Influences Force and Power Asymmetry During Jumping in Collegiate Athletes. J. Strength Cond. Res. 2014, 28, 884-891. [CrossRef] [PubMed]

44. Hoffman, J.R.; Ratamess, N.A.; Klatt, M.; Faigenbaum, A.D.; Kang, J. Do Bilateral Power Deficits Influence Direction-Specific Movement Patterns? Res. Sports Med. 2007, 15, 125-132. [CrossRef]

45. Rohman, E.; Steubs, J.T.; Tompkins, M. Changes in Involved and Uninvolved Limb Function During Rehabilitation After Anterior Cruciate Ligament Reconstruction: Implications for Limb Symmetry Index measures. Am. J. Sports Med. 2015, 43, 1391-1398. [CrossRef] [PubMed]

46. Campa, F.; Semprini, G.; Júdice, P.B.; Messina, G.; Toselli, S. Anthropometry, Physical and Movement Features, and Repeatedsprint Ability in Soccer Players. Int. J. Sports Med. 2019, 40, 100-109. [CrossRef] 
47. Whiteside, D.; Deneweth, J.M.; Pohorence, M.A.; Sandoval, B.; Russell, J.R.; McLean, S.G.; Zernicke, R.F.; Goulet, G.C. Grading the Functional Movement Screen: A Comparison of Manual (Real-Time) and Objective Methods. J. Strength Cond. Res. 2016, 30, 924-933. [CrossRef]

48. Bishop, C.; Read, P.; Chavda, S.; Jarvis, P.; Brazier, J.; Bromley, T.; Turner, A. Magnitude or Direction? Seasonal Variation of Interlimb Asymmetry in Elite Academy Soccer Players. J. Strength Cond. Res. 2020. [CrossRef] [PubMed]

49. Maloney, S.J.; Fletcher, I.M.; Richards, J. A comparison of methods to determine bilateral asymmetries in vertical leg stiffness. J. Sports Sci. 2015, 34, 829-835. [CrossRef]

50. Menzel, H.-J.; Chagas, M.H.; Szmuchrowski, L.A.; Araujo, S.R.; de Andrade, A.G.; de Jesus-Moraleida, F.R. Analysis of Lower Limb Asymmetries by Isokinetic and Vertical Jump Tests in Soccer Players. J. Strength Cond. Res. 2013, 27, 1370-1377. [CrossRef] [PubMed]

51. Pardos-Mainer, E.; Lozano, D.; Torrontegui-Duarte, M.; Cartón-Llorente, A.; Roso-Moliner, A. Effects of Strength vs. Plyometric Training Programs on Vertical Jumping, Linear Sprint and Change of Direction Speed Performance in Female Soccer Players: A Systematic Review and Meta-Analysis. Int. J. Environ. Res. Public Health 2021, 18, 401. [CrossRef] [PubMed]

52. Atkins, S.J.; Bentley, I.; Hurst, H.T.; Sinclair, J.K.; Hesketh, C. The Presence of Bilateral Imbalance of the Lower Limbs in Elite Youth Soccer Players of Different Ages. J. Strength Cond. Res. 2016, 30, 1007-1013. [CrossRef] [PubMed] 